\title{
DILEMAS E DESAFIOS DE REPUBLICANOS E DEMOCRATAS APÓS 2018
}

Tatiana Teixeira ${ }^{1}$

\begin{abstract}
A eleição presidencial de 2016 e seu resultado expuseram as fissuras de um sistema político cada vez mais polarizado e ferido por duros embates entre republicanos e democratas. Além disso, nos últimos anos, ambos os partidos também sofreram com o desgaste de suas disputas internas, entre conservadores, ultraconservadores, moderados e progressistas. Um dos mais visíveis e recentes sintomas dessa divisão - o "fator Trump" - se mantém como elemento perturbador da norma para muitos de seus correligionários e para seus adversários. Partindo de reflexões sobre as eleições de meio de mandato de 2018, este artigo pretende abordar os primeiros debates e movimentos para a eleição presidencial de 2020, olhando para os desafios e os já anunciados presidenciáveis republicanos e democratas.
\end{abstract}

Palavras-chave: Estados Unidos; eleições de meio de mandato 2018; eleições 2020; eleições americanas; partidos políticos; republicanos; democratas.

\section{CHALLENGES AND DILEMMAS FOR REPUBLICANS AND DEMOCRATS AFTER 2018}

The 2016 U.S. presidential election and its result exposed the deep divide in the U.S. political system. That has since become even more polarized as disputes between Republicans and Democrats intensify. That has been exacerbated in recent years as both parties suffer from internal disputes between conservatives, ultraconservatives, moderates and progressives. As one of the most visible symptoms of this divide, the 'Trump factor' continues to be a negative disruption of the political norm for many Republicans and almost all Democrats. Starting from the U.S. mid-term elections in 2018, this article will deal with the first debates and progress toward the 2020 presidential election, analyzing the challenges and candidates.

Keywords: United States; midterms 2018; U.S. elections 2020; American elections; political parties; republicans; democrats.

\section{DILEMAS Y DESAFÍOS DE REPUBLICANOS Y DEMÓCRATAS DESDE 2018}

La campaña de las elecciones presidenciales de 2016 y sus resultados expusieron las fisuras de un sistema político cada vez más polarizado y aquejado por las duras embestidas entre republicanos y demócratas. Los dos partidos sufrieron además en los últimos años el desgaste de sus disputas internas entre conservadores, ultraconservadores, moderados y progresistas. Uno de los síntomas más recientes y visibles de esa división, el "factor Trump", sigue siendo el elemento perturbador de la norma tanto para muchos de sus correligionarios como para sus adversarios. Este artículo pretende abordar, tomando como punto de partida las elecciones de medio mandato de 2018, los primeros debates y los movimientos de cara a las presidenciales de 2020, enfocándose en los desafíos y en los postulantes republicanos y demócratas.

Palabras clave: Estados Unidos; elecciones de medio mandato de 2018; elecciones en Estados Unidos; partidos políticos; republicanos; demócratas.

JEL: D72.

1. Editora no Observatório Político dos Estados Unidos (OPEU); e pesquisadora no Instituto Nacional de Ciência e Tecnologia para Estudos sobre os Estados Unidos (INCT-INEU).E-mail: <tatianat19@hotmail.com>. 


\section{INTRODUÇÃO}

Nos Estados Unidos, os partidos nascem, muito claramente - e isso se mantém com a passagem das décadas -, sem a obrigatoriedade de disciplina partidária e com uma distinção entre a agenda do partido no governo e as pautas de interesse de seus membros representados no Legislativo, mais conectados com as bases eleitorais e atentos às demandas dos movimentos de base, os chamados grassroots movements. Ainda assim, questóes conjunturais (guerras, crises econômicas e/ou financeiras, por exemplo), posiçôes sobre temas polêmicos (aborto, racismo, controle de armas, para citar alguns) ou bandeiras levantadas pelo ocupante na Casa Branca (Guerra Global ao Terror, reforma da Saúde, entre outros) podem levar a grandes mudanças no perfil do partido e daquele cidadáo que se identifica como seu eleitor.

No passado, a questão da escravidão, por exemplo, apresentou-se como um importante marco na ainda incipiente política partidária americana, levando à dissolução dos Whigs e à formação do Partido Republicano, novo abrigo de abolicionistas. Naquele momento, o país se fragmentava entre um norte, amplamente republicano e antiescravagista, e um sul, democrata agrário segregacionista, com estados fronteiriços e do Meio-Oeste politicamente divididos. Mais adiante, o crescimento populacional e das cidades e o maior número de imigrantes aumentariam a preocupação com o papel e com o tamanho que o governo federal deveria ter.

Em meio à Grande Depressão, o New Deal de Franklin Delano Roosevelt (FDR) e o debate sobre a maior ação do Estado estabeleceram uma divisão no eleitorado, com afro-americanos, judeus, católicos e trabalhadores sindicalizados votando nos democratas. Foi com o New Deal de FDR, na verdade, que o perfil dos partidos, tal qual entendemos hoje, começou a se consolidar. Em geral, os liberais democratas se manifestam a favor da atuação mais forte do governo na economia, com a defesa de programas sociais e a maior regulação, enquanto os conservadores republicanos preferem um Estado mais enxuto e menos interventor, menos regulação e uma maior participação dos agentes privados (Bianco e Canon, 2011).

Com Lyndon Johnson, sua plataforma Great Society e a reforma dos direitos civis, além da questão sobre o tamanho do Estado, o debate passou a incluir mais intensamente a discussão sobre temas sociais, como igualdade racial. Como lembram Bianco e Canon (2011, p. 226, tradução nossa), "um realinhamento começa com a emergência de uma nova questáo, ou debate, que captura a atenção de um grande número de cidadãos comuns, ativistas e políticos". ${ }^{2}$ E cada época tem sua questão crucial, que os partidos têm de enfrentar e à qual precisam se adaptar. 
Segundo Monkovic (2016), marcada pela adesão democrata ao movimento dos direitos civis, a eleição de 1964 trouxe a guinada do Sul para os republicanos. Foi a primeira vez, desde os anos 1870, que o Grand Old Party (GOP, denominação que remete ao Partido Republicano) conquistou o Deep South (o Sul Profundo dos estados do Cinturão do Algodáo), vencendo na Geórgia, no Alabama, na Carolina do Sul, no Mississippi e em Louisiana. O perfil do eleitorado sofreu, assim, um novo alinhamento, decorrente de um ressentimento étnico, racial e social de sulistas brancos democratas (Boyd, 1970), em um contexto de grande efervescência na sociedade e com a prolongada duração da Guerra do Vietná como pano de fundo. Assim, formou-se um desenho ainda mais parecido com o dos tempos presentes: sulistas brancos e cristãos procurando os republicanos, e as minorias - sobretudo afro-americanos e cidadãos de origem hispânica - identificando-se mais com os democratas. A questão racial se tornaria, ao longo das décadas, um dos elementos definidores nas eleiçóes americanas.

Desde o início dos anos 1990, afirma Pecequilo (2017, p. 342-345), o Partido Democrata tem-se dividido entre uma agenda mais "liberal de esquerda" e uma de "centro". No primeiro caso, significa, conforme mencionado anteriormente, posicionar-se pelo welfare state, "provendo serviços sociais, como educação, saúde, infraestrutura, e a inclusão política de grupos de interesse das mais diversas origens étnicas, raciais e de gênero", assim como adotar uma "visão secular da política, com baixa aderência a um discurso religioso". Essa seria a posição do senador Bernie Sanders (I-VT), ${ }^{3}$ derrotado pela ex-secretária de Estado Hillary Clinton em 2016. Em relação ao "centro", completa Pecequilo (op. cit., p. 346), seguem-se essas mesmas tendências, mas "sem excesso de particularismos, com moderação, tentando preservar as contas públicas e a hegemonia ao mesmo tempo". Nesse grupo, a autora inclui os ex-presidentes Bill Clinton (1993-2000) e Barack Obama (2008-2016), assim como a ex-senadora Hillary.

Além do Estado mínimo, com corte de impostos e refratário a políticas voltadas para a população de baixa renda (rotuladas como "assistencialistas"), o mainstream republicano tem "uma identificação mais direta com posturas religiosas no que se refere a comportamentos", com a defesa da família e dos valores tradicionais e, "em termos sociais, étnicos e raciais, em linhas gerais, o partido identificava-se com a tradição WASP, ${ }^{4}(. .$.$) sem forte apelo às minorias"$ (Pecequilo, 2017, p. 342-343).

Mais recentemente, em 2008, a vitória de Obama fez os democratas entenderem literalmente a adesão dos eleitores ao mote Yes, We Can. O entusiasmo

3. Usa-se assim para se referir ao partido (I quer dizer independente; D, democrata; e R, republicano) e ao estado (o leitor pode conferir o significado das siglas na observação da figura 1 deste artigo).

4. White, anglo-saxon and protestant (branco, anglo-saxão e protestante). 
com a mensagem de esperança e de mudança foi real, mas se tratou, acima de tudo, de um voto antiBush, contra a guerra no Iraque e contra a crise econômica, e não contra o status quo. Não foi um voto para mudar tudo (Teixeira, 2011). A agenda social de Obama, o primeiro afro-americano a chegar à presidência dos Estados Unidos, foi oferecendo elementos e abrindo espaço, a partir de 2010, para a formação de um movimento radicalizado dentro do GOP: o Tea Party.

Este movimento inseriu-se instrumentalmente no Partido Republicano, com uma agenda libertária, religiosa, antigoverno, antissistema, contra o aborto, contra a ampliação de direitos civis, gênero e raça, pró-armas, isolacionista e belicista (caso necessário) (Pecequilo, 2017, p. 350).

Menos barulhento nos dias atuais, o Tea Party é lembrado como um grupo bastante importante para a contenção das políticas promovidas por Obama, especialmente sua reforma da Saúde, assim como um facilitador das condiçóes que tornaram possíveis e palatáveis a candidatura e a vitória do magnata republicano (Bannon, 2018). Ambos, Tea Party e Trump, têm a mesma agenda contra o establishment e o pântano washingtonianos, os imigrantes, o Obamacare e os elevados deficit federais (op. cit.). E, assim como Trump, aponta Mead (2011a, traduçáo nossa), esse movimento teria origem no populismo jacksoniano, rebelando-se contra "a emergente realidade de um Estados Unidos multicultural e multirracial e uma nova era de ativismo governamental", contra "elites mal orientadas e corruptas" e contra o "internacionalismo liberal".

Nas eleiçôes de meio de mandato (midterms) de 2006, os democratas haviam conseguido o controle das duas casas. Com as eleiçóes de 2008, esses ganhos foram reforçados (257 democratas e 178 republicanos na Câmara; 58 democratas e 41 republicanos no Senado), obtendo-se um aumento no número de representantes e uma entrada ainda maior entre os eleitores jovens e independentes. Em 2010 (e em 2014), porém, Obama sofreu uma grande derrota na Câmara (193 democratas contra 242 republicanos), com um ativo Tea Party conseguindo mobilizar as bases e colaborando "para uma onda de sentimento contra o big government que fez das eleiçóes de 2010 uma derrota significativa para os democratas" (Mead, 2011b, tradução nossa).

Mesmo com a pressão nas midterms, esse resultado não impediu a reeleição de Obama, do mesmo modo que não impediu a de Bill Clinton, em 1996, que passara pelo mesmo estrago político. Como lembram Galston e Hendrickson (2019), vitórias e derrotas nas eleiçóes de meio de mandato estão longe de serem determinantes para o próximo ciclo eleitoral - e isso vale para ambos os partidos. Em 1982, por exemplo, apesar das grandes perdas, Ronald Reagan acabou reeleito dois anos depois.

A disputa presidencial de 2016 e seu resultado expuseram as fissuras de um sistema político que veio se polarizando cada vez mais, ferido por duras disputas 
inter e intrapartidárias e por fortes embates entre o Legislativo e o Executivo, com efeitos que ressoaram até as midterms de 2018. O "fator Donald Trump" não contribuiu apenas para aumentar a participação em eleiçóes que normalmente despertam pouco interesse da população americana e que, desta vez, registraram quase 50\% de "comparecimento" (é importante lembrar que, nos Estados Unidos, os votos podem ser enviados inclusive pelo correio). Sua chegada à presidência gerou uma contrarreação social e política, entre os democratas e também em suas próprias fileiras, o que ajudou a diversificar o perfil dos congressistas eleitos.

As eleições de meio de mandato de novembro de 2018 resultaram em uma Câmara de Representantes com um número recorde de mulheres, com nomes como a autointitulada democrata-socialista Alexandria Ocasio-Cortez (D-NY), Ilhan Omar (D-MN) ou Rashida Tlaib (D-MI), com mais políticos progressistas e pragmáticos, mais jovens, uma maior presença afro-americana e hispânica, entre outras minorias étnico-raciais e religiosas - uma mudança que se estendeu aos níveis estaduais, municipais e locais, tanto no Executivo quanto no Legislativo. Em uma proporção similar a números de 2014 e de 2016, em 2018, quase $80 \%$ de negros, latinos e americanos de origem asiática votaram nos democratas (Brady, Rivers e Parker, 2019).

A expectativa é que esse novo perfil da Câmara tenha um impacto considerável nas políticas domésticas. Ao mesmo tempo, esse resultado trouxealgumas indefiniçóes e questóes, com as quais ambos os partidos terão de lidar antes do próximo pleito eleitoral. "Os dois partidos passam por fenômenos similares: a tentativa de manter sua identidade em meio a fragmentaçôes, que revelam disputas intrapartidárias crescentes e a renovação" (Pecequilo, 2017, p. 345). Nos democratas, a manutenção de tropas no Iraque e no Afeganistão ou a reforma da Saúde e sua amplitude podem ser pautas contenciosas. Já entre os republicanos, dois temas sensíveis e que provocam dissidências em votaçôes cruciais são a imigração e qualquer medida referente à prática do aborto, entre outros.

Ainda sobre 2016, o "fator Bernie Sanders" é outro elemento de irradiação prolongada a ser levado em conta quando se considera, em especial no Partido Democrata, o grande número de políticos com agenda progressista que pretendem disputar a Casa Branca em 2020, incluindo o próprio Sanders. Com os novos eleitos na Câmara, seus discursos e propostas - a favor de igualdade salarial, Medicare para todos, ensino superior gratuito, salário mínimo de US\$ 15 a hora, políticas para atenuar a mudança climática e mais regulação e impostos sobre as grandes corporaçóes e grandes fortunas - ganham voz e espaço. Um excesso de pautas que pode enfraquecer o campo democrata e abrir flancos vulneráveis na disputa com Trump e seus slogans simples, suas frases curtas, seu vocabulário reduzido e suas promessas de fácil compreensão. 
Partindo de reflexóes sobre 2018, este artigo pretende abordar os primeiros movimentos para a eleição presidencial de 2020, olhando para desafios e os já anunciados presidenciáveis republicanos e democratas.

\section{PROGRESSISTAS OU MODERADOS: A DIFÍCIL ESCOLHA DEMOCRATA}

Em 2016, havia cinco pré-candidatos, todos homens, disputando a indicação do partido com Hillary. Este ano, até maio, eram 23 nomes confirmados, mais outros potenciais concorrentes e suas plataformas parecidas, com distinçōes de ênfase, sobre saúde universal, redução da desigualdade socioeconômica, melhores condiçóes de vida para a classe média, aumento da regulação no setor ambiental, entre outros temas caros à sigla. Esse número recorde de pré-candidatos deve ser encarado, primeiramente, como um dos sintomas de um partido em crise que ainda não digeriu a derrota em 2016 e continua buscando explicaçóes e culpados para a ascensão do "fator Trump". Também pode ser visto como tentativas individuais de seus políticos de entender essas mudanças e atender às recentes e diversas demandas de movimentos sociais. Desde o início do governo Trump, viu-se, em várias capitais do país, uma multidão de jovens indo às ruas contra a violência policial, de gênero e de raça, contra as armas ou contra o aquecimento global.

Para a maioria desses presidenciáveis, ainda que as chances sejam diminutas, passar pelas primárias pode ser uma experiência valiosa: aumenta a visibilidade no plano nacional, ao marcar uma posição contra o governo da situação; oferece um espaço de possibilidade para a exposiçáo e a defesa de novos temas e agendas; e ajuda a ampliar o peso político no partido e a conquistar novos doadores para futuras campanhas.

A vitória na Câmara nas midterms de 2018 trouxe um novo ânimo para os democratas, que veem um Trump inconsistente nas pesquisas de aprovação em nível nacional (uma média de $43 \%$ ) $^{5}$ e perseguido pela sombra de uma tentativa de processo de impeachment que uma ala da legenda insiste em manter à espreita. Com o resultado da investigação do procurador especial Robert Mueller, isentando o presidente de envolvimento no Russiagate (mas náo exatamente de obstrução de justiça), essa pauta perde força. Mais do que isso: é algo que pode dividir e desgastar o partido, como alertou algumas vezes a atual presidente da Câmara, Nancy Pelosi (D-CA).

Em um panorama que mostra os democratas ainda perdidos, a leitura da Casa Branca é que será mais fácil derrotar candidatos que sejam marcadamente progressistas, como Elizabeth Warren ou Bernie Sanders, e não mais moderados, como Joe Biden. Até agora, o ex-vice tem sido o alvo preferencial dos ataques de

5. Média das pesquisas feita pelo site RealClearPolitics. Disponível em: <https://www.realclearpolitics.com/epolls/ other/president_trump_job_approval-6179.html>. Acesso em: maio 2019. 
Trump. Ainda não é possível afirmar se esta é a melhor análise ou apenas a mais previsível. O fato incontestável por enquanto é que essas primárias se anunciam como as mais disputadas do partido, com muitos rostos novos e novas formas de fazer política (Ball e Elliott, 2019; Cillizza, 2019). Talvez a chapa vencedora seja aquela que consiga estabelecer mais pontes entre os diferentes grupos que vão se formando. Em última análise, trata-se, agora, pragmaticamente, de ser o melhor candidato para derrotar Trump, sendo ou não a preferência da cúpula do partido ou da base eleitoral.

Depois da amarga derrota de Hillary, uma questão ése os americanos estariam, enfim, preparados para colocar uma mulher na presidência, ou se é melhor optar pelo caminho seguro e investir em alguém com um perfil mais próximo ao de Trump, de 72 anos: homem, branco, mais velho, ou que se identifique e seja percebido como um outsider da política e crítico do establishment washingtoniano. Longe de ser banal, ou periférica, a questão de gênero foi um dos elementos do debate na recente corrida pela Casa Branca, em especial nos diferentes modos de tratamento concedidos à ex-senadora e ao ex-apresentador de reality show, por parte da imprensa americana, de políticos, de doadores ou do público.

Também se coloca, para o Partido Democrata, o quão à esquerda seus candidatos podem ir sem afastar a parte mais moderada do eleitorado, sejam correligionários, independentes, nose-holders (não republicanos que votaram em Trump apenas por considerá-lo menos pior que Hillary), ou mesmo republicanos insatisfeitos com o presidente. $\mathrm{Na}$ média, o eleitor americano ainda é mais conservador que progressista, com $35 \%$ contra 26\%, respectivamente, de acordo com pesquisa Gallup referente a 2018 (Saad, 2019). E, embora os entusiastas da chamada onda azul possam comemorar o fato de, pela primeira vez, segundo a mesma enquete, os democratas autodeclarados politicamente liberais (51\%) serem maioria, $34 \%$ se identificam como moderados e $13 \%$ como conservadores.

Em fevereiro, o mesmo instituto divulgou uma pesquisa mostrando que o partido manteve uma tendência de migrar cada vez mais para a esquerda, impulsionado pelos eleitores brancos de maior escolaridade (Saad, Jones e Brenan, 2019). Em 2001, relata a Gallup, $42 \%$ dos democratas se definiam como moderados; 32\% como liberais; e 23\% como conservadores. Quase duas décadas depois, em 2018, 46\% se diziam liberais e 17\%, conservadores. Cada vez mais democratas brancos se colocam no primeiro grupo, contra uma minoria de democratas negros e de origem hispânica que se identifica como liberal. Ainda de acordo com a enquete, questóes como o aumento de impostos para os mais ricos e para as grandes empresas e o controle de armas ou a mudança climática são bem-vindas para os eleitores das três categorias, enquanto gastos em defesa, aborto ou sistema de saúde pública são mais controversos, especialmente entre os mais conservadores e os mais progressistas dentro da sigla. 
Por enquanto, a cúpula partidária ensaia movimentos de contenção do que começa a ser apontado como crescentes "radicalismo" e "ortodoxia ideológica" dentro da legenda, ou um processo de "contágio do Tea Party" - só que à esquerda (Rothman, 2019). Segundo esse autor, o Comitê de Campanha Democrata ao Congresso já teria anunciado que restringiria seu apoio a pré-candidatos progressistas nas primárias. $\mathrm{Na}$ Câmara de Representantes, a presidente da Casa e outros caciques insistem na moderação em debates e na apresentaçâo de propostas sobre temas sensíveis, como a abertura de um processo de impeachment contra Trump, o Green New Deal, a reforma migratória ou o Medicare for All.

No caso democrata, como parte do processo de se pensar na identidade partidária, é importante contrapor e reformular narrativas que estâo sendo construídas sobre rótulos e posicionamentos do espectro político, ou seja, o que significa, nos Estados Unidos, ser "moderado" e de "centro", "progressista", "liberal de esquerda", "radical" ou "socialista-democrata", quais nomes estão sendo colocados nessas categorias, por quem e com quais propósitos. A publicidade divulgada por comitês e organizaçôes durante as campanhas eleitorais americanas, principalmente quando se trata da briga pela presidência, pode ser bruta e preconceituosa. Candidatos são demonizados e difamados, e biografias, programas de governo e declaraçóes, muitas vezes, distorcidos.

Uma das já anunciadas estratégias de campanha de Trump será se referir ao potencial rival democrata como "socialista", "extremista" ou de "extrema esquerda", ou ainda usar motes como "salvar o país do socialismo", "eu vou proteger vocês", "nossos valores e interesses estão sob ataque". O objetivo é estimular uma base eleitoral conservadora, que permanece insatisfeita com as mudanças econômicas, culturais e demográficas do país, a votar em massa e, ao mesmo tempo, se possível, atrair o centro (Bremmer, 2019; Brownstein, 2019b; Snell, 2019). No entanto, mais do que se concentrar em conquistar novas fatias do eleitorado e tentar convencer quem está em dúvida ou pensa diferente do magnata nova-iorquino, a diretriz, até o momento, é expandir a participação de quem pensa igual (Allen, 2019).

A política de campanha de Trump promete ser a do medo e da conspiração.

\section{A LONGA LISTA DE PRESIDENCIÁVEIS DEMOCRATAS}

Mais conhecido nacionalmente entre todos os demais concorrentes, o ex-vice-presidente Joe Biden, de 76 anos, tem aparecido como o mais bem colocado na maioria das pesquisas. Em uma sondagem realizada no início de maio pela HarrisX em parceria com o The Hill, por exemplo, ele registrava 46\% das intençóes de voto, à frente de Bernie Sanders, com 14\%; Pete Buttigieg, com 8\%; Elizabeth Warren, com 7\%; Kamala Harris, com 6\%; e Beto O’Rourke e Cory Booker, com 3\% cada (Sheffield, 2019). 
Um ponto vulnerável de Biden é sua idade (ele terá 78 anos na posse, em 2021). É um político da velha-guarda, homem e branco, atributos que destoam do momento de transformaçáo pelo qual o Partido Democrata parece passar e que preconiza, na voz dos novos eleitos e eleitas, igualdade de gênero e racial, justiça social e maior representatividade política. Anybody but a white guy 2020 (qualquer um menos um cara branco em 2020, em tradução livre) é um dos slogans que aparecem com frequência nos eventos com millenials e ativistas pelos direitos das minorias. Biden já disputou a presidência duas vezes. Alguns de seus registros de votaçáo como senador (D-DE), incluindo seu apoio à guerra no Iraque, podem ser considerados problemáticos entre os eleitores mais jovens. Em contrapartida, o período na Casa Branca e seu perfil de político acessível, com penetração especialmente na classe trabalhadora, além do bom volume de doaçôes de campanha que teria conseguido até agora, são vistos como aspectos positivos (Teixeira, 2019).

O senador Bernie Sanders (I-VT), de 77 anos, continua entre os primeiros, mas a vantagem diminuiu. Enfrentará, possivelmente, o rancor dos eleitores da ex-senadora Hillary e a ira dos trumpistas, mas tem a vantagem de já ter projeção nacional. Assim como para Biden, a idade avançada pode ser um problema. Um anúncio muito esperado foi o do ex-representante Beto O’Rourke (D-TX), de 46 anos, que ganhou visibilidade ao quase derrotar o senador Ted Cruz (R-TX) no ano passado. Defensor da unidade nacional, da reforma migratória e da legalização da maconha, também tem bastante apelo entre os jovens.

A ex-procuradora-geral da Califórnia e senadora Kamala Harris (D-CA), de 54 anos, já conta com a adesão de vários correligionários de seu estado, de perfil claramente democrata há anos e com grande peso em número de delegados no colégio eleitoral. Kamala ganhou mais visibilidade na firme sabatina no Senado ao último indicado de Trump à Suprema Corte, o polêmico juiz Brett Kavanaugh (Teixeira, 2019). Se vencer, será a primeira mulher afro-americana de origem indiana a chegar à Casa Branca. A senadora e ex-professora da Universidade de Harvard Elizabeth Warren (D-MA), de 69 anos, apresenta-se como uma das mais bem preparadas para o cargo, com um conhecimento em regulação financeira reforçado por seu discurso crítico à desigualdade de renda, contra a corrupção e a favor de uma classe média sob constante ataque das grandes empresas. Já esteve no centro de uma polêmica envolvendo suas origens ameríndias. Ainda que esclarecido, o caso foi amplamente usado por Trump e poderá servir de munição para os adversários.

Após um elogiado discurso na Convençáo Nacional Democrata de 2016, o agora ex-prefeito por Newark e senador Cory Booker (D-NJ), de 49 anos, chegou a ser apontado como um "futuro Obama". Hoje, divide opinióes no partido. Também conta com uma ampla base de arrecadaçáo de doaçóes de campanha. 
No Senado, uma de suas principais bandeiras é a reforma da justiça criminal, assim como o discurso pela unidade e pela ação coletiva. $O$ veterano da guerra no Afeganistão e prefeito de South Ben (Indiana), Pete Buttigieg, de 37 anos, é o mais jovem na corrida presidencial, à frente de uma cidade conservadora. Nos Estados Unidos, segundo a Constituição, a idade mínima para concorrer à presidência é 35 anos. Sua plataforma de campanha prioriza temas que têm mobilizado principalmente os millenials, como a mudança climática e a reforma sobre a posse de armas. Se eleito, será o primeiro presidente abertamente homossexual do país.

A senadora Amy Klobuchar (D-MN), de 58 anos, anunciou sua candidatura em Minneapolis, um importante reduto eleitoral. Sua agenda inclui a volta dos Estados Unidos ao Acordo de Paris, um sistema de saúde universal e, assim como Booker, a reforma da justiça criminal. Pesa a seu favor o bom desempenho em uma parte do Meio-Oeste que ajudou a levar Trump à vitória em 2016. A também senadora Kirsten Gillibrand (D-NY), de 52 anos, engrossou a lista de pré-candidatos. Ficou mais conhecida por sua participação no movimento $\mathrm{Me}$ Too, que denuncia o assédio e a violência contra as mulheres, mas ainda tem pouca expressividade e, nesse início da corrida, tampouco conta com o apoio manifesto de seus correligionários locais, ao contrário do que já acontece com seus colegas de outros estados.

Outros nomes também já confirmaram sua pré-candidatura. ${ }^{6}$

O ex-secretário da Habitação e de Desenvolvimento Urbano e ex-prefeito de San Antonio (Texas), Julián Castro, de 44 anos, é neto de um imigrante mexicano e o único de origem hispânica na disputa. O ex-representante John Delaney (D-MD), de 55 anos, faz uma intensa campanha em Iowa desde o ano passado e foi o primeiro a se apresentar. A veterana da Guarda Nacional do Exército e representante Tulsi Gabbard (D-HI), de 37 anos, primeira hindu na Câmara, já se envolveu em uma polêmica por sua defesa do presidente sírio, Bashar al-Assad, com quem se reuniu em 2017.

Autodeclarado de "centro", o ex-governador do Colorado John Hickenlooper, de 67 anos, ostenta indicativos econômicos de sua gestáo e sua pauta progressista, com a aprovação de uma legislação pelo controle de armas, pela legalização da maconha e pela expansão do sistema de saúde. O governador de Washington, Jay Inslee, de 68 anos, aparece com uma plataforma com medidas contra a mudança climática. Primeiro prefeito negro de Miramar, na Flórida, Wayne Messam, de 44 anos, promete adotar medidas para diminuir a violência armada e a mudança

6. Lista atualizada dos pré-candidatos democratas e republicanos disponível em: <https://www.nytimes.com/ interactive/2019/us/politics/2020-presidential-candidates.html>. Acesso em: maio 2019. 
climática, cancelar a gigantesca dívida estudantil (US\$ 1,5 trilhão) e trazer de volta o "sonho americano".

Completavam a lista, até maio de 2019: o prefeito de Nova Iorque, Bill de Blasio, 58 anos; os representantes Tim Ryan (D-OH), 45 anos, Eric Swalwell (D-CA), 38 anos, e Seth Moulton, (D-MA), 40 anos; o senador Michael Bennet (D-CO), 54 anos; o ex-senador Mike Gravel (D-Al), 88 anos; o ex-procurador-geral estadual e governador de Montana, Steve Bullock, 53 anos; a autora de livros de autoajuda Marianne Williamson, 66 anos; e o ex-executivo do setor de tecnologia Andrew Yang, 44 anos, que promete adotar uma renda mínima universal de US\$ 1 mil por mês.

\section{0 "FATOR TRUMP" NAS FILEIRAS REPUBLICANAS}

Em 2016, eram dezesseis pré-candidatos na corrida contra Donald Trump, o menos provável de chegar à Casa Branca. A vitória veio, sobretudo, pelo rompimento do "paredão azul" de 242 votos no colégio eleitoral garantidos pelos adversários desde 1992: ${ }^{7}$ os democratas obtiveram apenas 232 votos, contra os 306 da chapa Trump e Mike Pence (Galston e Hendrickson, 2019). Ao contrário de Barack Obama em 2008 e em 2012, Hillary não conseguiu manter os votos no Cinturão da Ferrugem (Rust Belt), perdendo os importantes Wisconsin, Michigan, Pensilvânia, Iowa e Ohio. Em muitos estados, a disputa foi bastante acirrada: menos de 1\% nos três primeiros citados (redutos democratas de 1992 a 2012), assim como em Nova Hampshire, e menos de 5\% em outros sete, incluindo Minnesota, Maine e Arizona.

Nesse sentido, as midterms de 2018 trouxeram alguma esperança aos democratas, com seus bons desempenhos em Wisconsin, Michigan e na Pensilvânia, entre os swing voters, ou ainda entre as mulheres escolarizadas que vivem nos subúrbios e os jovens. Para Galston e Hendrickson (2019), os números de 2018 em Wisconsin, Michigan e Pensilvânia não significam um realinhamento republicano definitivo.

O empresário nova-iorquino contou, principalmente, com o voto do americano branco de baixa escolaridade e/ou sem formação universitária, evangélico, que vive nas áreas rurais, em cidades menores e no Meio-Oeste, região que inclui alguns estados do decadente Cinturão da Ferrugem. Além da crescente divisão de preferências em função do nível educacional, acentuou-se, com a eleição de Trump, a distinção entre o eleitor rural (pró-republicanos) e o eleitor dos centros urbanos (pró-democratas). Vários estados onde o magnata

7. Mais informações e mapas disponiveis em: <www.270towin.com/content/blue-and-red-states>. 
nova-iorquino foi eleito, como Iowa e Wisconsin, contam com uma grande parcela de eleitores nessas áreas (Kurtzleben, 2016).

No GOP, o "fator Trump" também teve seus efeitos e ainda não é algo resolvido internamente. Como argumenta Bacon Junior (2019), ao contrário dos democratas, com suas divisóes internas sobre a própria agenda do partido, para os republicanos, mais coesos nesse sentido, a questáo não seria mais ser contra ou a favor de Trump, ou entre moderados, conservadores e radicais (Tea Party e House Freedom Caucus, por exemplo). Hoje, trata-se basicamente "do quanto aderir ao trumpismo". Para definir o termo, Bacon Junior (2019) se volta para áreas com medidas adotadas pelo atual presidente que destoam de seus antecessores da mesma sigla: anti-institucionalismo (ataques ao departamento de Justiça, à imprensa ou à comunidade de Inteligência); protecionismo econômico (guerras comerciais e saída de acordos); política externa (hostilidade à Organização do Tratado do Atlântico Norte - OTAN - e a parceiros históricos, por exemplo); além de questóes migratórias (construção do muro na fronteira com o México, ou travel ban). ${ }^{8}$

Entre idas e vindas, concordando ou não com as medidas e com o estilo trumpista, por cálculos de sobrevivência eleitoral no curto e no médio prazo, a cúpula do GOP começou a cerrar fileiras para proteger a reeleição de Trump (Thompson, 2019). O objetivo é evitar uma cisão interna dramática o suficiente a ponto de ameaçar um segundo mandato, o que poria em risco a manutenção e a ampliação dos termos da agenda conservadora. Membros do Comitê Nacional Republicano já aprovaram uma resolução, anunciando o "apoio incondicional" a Trump, e adotaram medidas extras para sufocar o movimento Never Trump, enquanto na Carolina do Sul membros do partido manifestaram seu apoio ao cancelamento da primária, com o objetivo de minar potenciais desafiadores ao presidente (Wood, 2019).

Historicamente, presidentes desafiados nas primárias pela reeleição acabam enfraquecidos e derrotados nas urnas. Ainda assim, alguns (poucos) nomes dissidentes, mais ligados aos republicanos tradicionais, começam a surgir como potenciais concorrentes nas primárias do partido. Especula-se sobre os anúncios de dois duros críticos de Trump, o ex-governador de Ohio John Kasich e o ex-senador Jeff Flake (R-AZ), além do governador de Maryland, Larry Hogan,

8. Assim que tomou posse, o presidente Trump sancionou a ordem executiva Protecting the Nation from Foreign Terrorist Entry into the United States, proibindo a entrada de imigrantes e não imigrantes de sete países de maioria muçulmana - Irã, Líbia, Somália, Sudão, Síria, lêmen e Iraque -, assim como de refugiados. Em meio a batalhas judiciais e acusações de preconceito, o governo chegou a aprovar uma terceira versão, incluindo Coreia do Norte, Venezuela e Chade. Este último foi retirado da lista, a qual acabou sendo mantida em uma apertada votação na Suprema Corte. Em 2018, mais de 37 mil pedidos de visto que estariam nessa categoria foram rejeitados. 
e dos senadores Mitt Romney (R-UT), derrotado por Obama em 2012, e Ben Sasse, do Nebrasca (Smith e Pilkington, 2019; Wood, 2019).

$\mathrm{O}$ único a anunciar sua pré-candidatura por enquanto foi o ex-governador de Massachusetts Bill Weld, de 73 anos, vice na chapa do libertário Gary Johnson na disputa pela Casa Branca em 2016. No pronunciamento feito em Bedford, Nova Hampshire, onde aconteceu a primeira primária, Weld ecoou um dos slogans mais consensuais entre os democratas, afirmando que Trump é uma "ameaça à democracia americana” (Pilkington, 2019, tradução nossa). Sem chances reais, a candidatura está sendo vista mais como um ato de protesto (Burns, 2019).

Problemas para qualquer um que tente desafiar Trump: i) a situação da economia (embora analistas antecipem uma desaceleração para 2019 e o trabalhador americano veja seu poder de compra se deteriorar no governo atual, o índice de desemprego permanece baixo, a uma média de $4 \%$, e a percepçáo ainda é de que a economia vai bem); ii) a aprovação do presidente entre os eleitores republicanos continua alta (apesar da média nacional de cerca de $40 \%$, entre os correligionários sua aprovaçáo beira os $90 \%$ ); ${ }^{9}$ iii) o empresário nova-iorquino tem a máquina política a seu favor e recursos financeiros consideráveis para investir na própria campanha, assim como ampla cobertura da imprensa; iv) seu estilo eventualmente virulento, agressivo e imprevisível baixa o nível dos debates e contribui para incitar o ódio em comícios, como se viu em 2016 e em 2018 (Stolberg, 2019); e $v$ ) a "indústria" de fake news nas redes sociais continua ativa e a postos.

\section{CONSIDERAÇÕES FINAIS: RUMO A 2020}

Nos Estados Unidos, onde o voto não é obrigatório, a eleição para presidente acontece de forma indireta. Os eleitores votam, na verdade, nos 538 delegados do colégio eleitoral, os quais, estes, sim, escolherão o novo presidente. $\mathrm{O}$ número de delegados de cada estado é proporcional ao de sua população e ao total de representantes (deputados) e de senadores das unidades federativas. Com a exceção de Maine e Nebrasca, em 48 dos 50 estados e em Washington, vale o sistema de "o vencedor leva tudo", ou seja: aquele que tiver o maior número de votos é o vencedor. Para se eleger presidente, o candidato precisa obter no mínimo 270 votos dos delegados. Em 2016, cerca de 138 milhóes de eleitores foram votar.

Na maioria dosestados, o perfil político-sedemocrata, se republicano-costuma ser o mesmo há várias eleiçôes. Alguns estados são emblemáticos. Desde 1992, por exemplo, os democratas ganharam todas as eleições na Califórnia, que concede 55 delegados. No Texas, estado que concede 38 votos, os republicanos vencem desde os anos 1980. A partir de 2016, porém, os texanos começaram a demonstrar um

9. Comparações com outros presidentes e uma linha do tempo da aprovação no governo Trump disponíveis em: $<$ https://is.gd/7hSe1r> e <https://is.gd/sQ566l>. 
comportamento eleitoral menos rígido, com Hillary perdendo por uma margem menor que Obama em suas duas corridas eleitorais.

Para aumentar suas chances, os (pré-)candidatos investem esforços, tempo e recursos de campanha nos chamados swing states, estados indecisos altamente competitivos, onde é possível ganhar o jogo (figura 1). Entre eles estão Flórida, com 29 votos; Pensilvânia, com 20; Ohio, com 18; Geórgia, com 16; Carolina do Norte, com 15; Virgínia, com 13; Colorado, com 9; Nevada, com 6; e Iowa, com 6.

\section{FIGURA 1}

\section{Filiação partidária por estado (2018)}

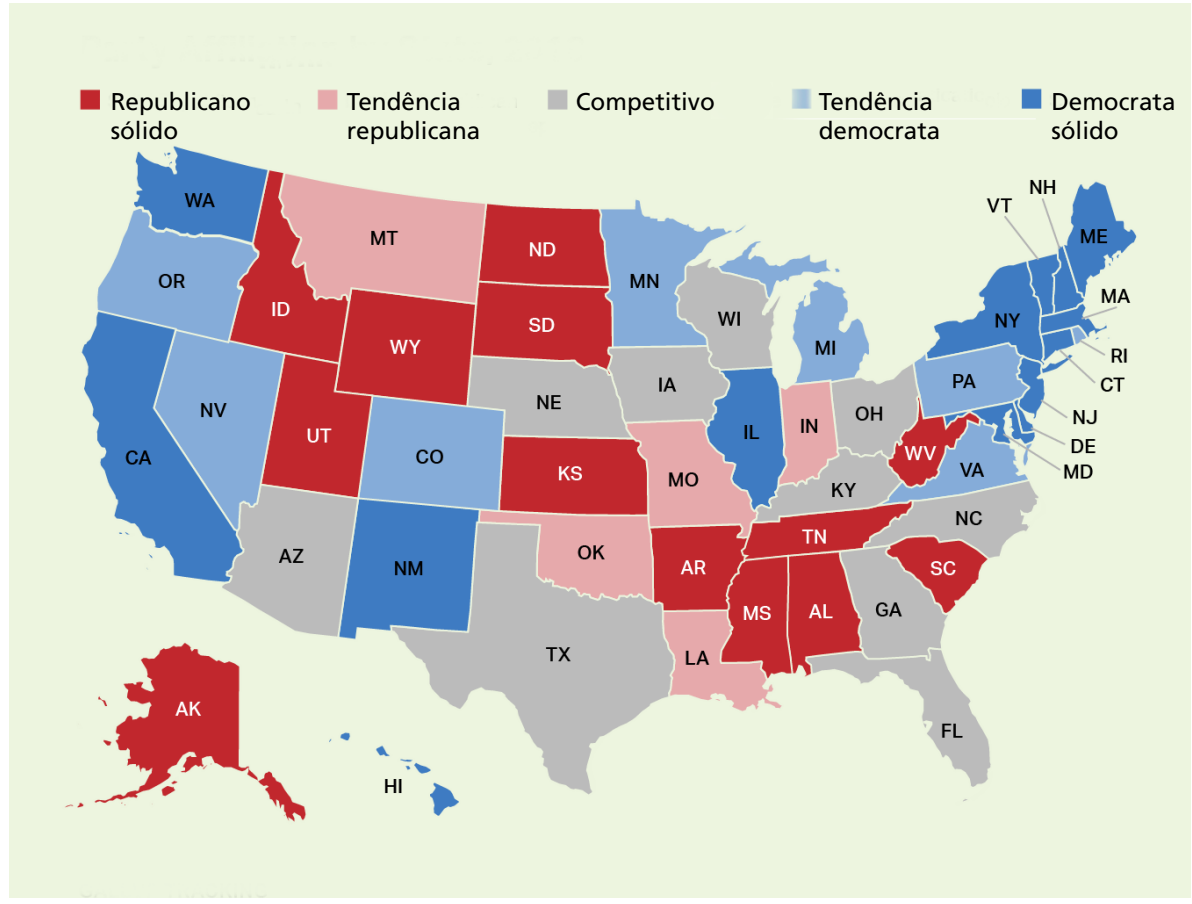

Fonte: Jones (2019).

Obs.: AK - Alasca; AL - Alabama; AR - Arkansas; AZ - Arizona; CA - Califórnia; CO - Colorado; CT - Connecticut; DE - Delaware; FL - Flórida; GA - Geórgia; HI - Havaí; IA - Iowa; ID - Idaho; IL - Illinois; IN - Indiana; KS - Kansas; KY - Kentucky; LA - Louisiana; MA - Massachusetts; MD - Maryland; ME - Maine; MI - Michigan; MN - Minnesota; MO - Missouri; MS - Mississippi; MT - Montana; NC - Carolina do Norte; ND - Dakota do Norte; NE - Nebrasca; NH - Nova Hampshire; NJ - Nova Jersey; NM - Novo México; NV - Nevada; NY - Nova lorque; OH - Ohio; OK - Oklahoma; OR - Óregon; PA - Pensilvânia; RI - Rhode Island; SC - Carolina do Sul; SD - Dakota do Sul; TN - Tennessee; TX - Texas; UT - Utah; VA - Virgínia; VT - Vermont; WA - Washington; WI - Wisconsin; WV - Virgínia Ocidental; WY - Wyoming.

Para 2020, estrategistas de campanha de ambos os partidos veem o Rust Belt e o Sun Belt (Cinturão do Sol) como potentes campos de batalha. No caso do primeiro, grande responsável pela ascensão de Trump, na comparação em nível nacional, pesquisas de 2018 mostravam um desempenho local pior do presidente 
entre os eleitores brancos e sem diploma universitário, oferecendo uma brecha para os democratas (Brownstein, 2019a). No segundo, em estados como Arizona, Flórida e Carolina do Norte, é alta a aprovação média do republicano entre os eleitores brancos com ou sem formação universitária (Brownstein, 2019a). À exceção do Arizona, o resultado obtido pelos democratas na regiâo decepcionou. Assim, acrescenta o mesmo autor, um início de caminho para os democratas seria mobilizar a crescente população não branca que avança nessa região a passos mais largos que no Rust Belt.

Entre as estratégias democratas, uma delas é dar atenção especial às questôes econômicas para, dessa forma, conquistar "eleitores brancos insatisfeitos no Meio-Oeste - especialmente das famílias trabalhadoras com a renda estagnada - e estimular a participação entre os eleitores não brancos no Sun Belt, particularmente jovens" (Brownstein, 2019a, tradução nossa). As prioridades democratas seriam Wisconsin, Michigan e Pensilvânia, estado de Joe Biden, natural de Pittsburgh, onde lançou sua pré-candidatura. A expectativa é que a participação nas urnas seja ainda maior do que foi em 2016, com um eleitorado mais jovem (a chamada geração Z) e menos branco (Brady, Rivers e Parker, 2019; Cilluffo e Fry, 2019) um perfil que, em geral, beneficia os democratas. Ainda que pesquisas de opinião e índices de aprovação digam o contrário, porém, a permanência de dados econômicos favoráveis e uma forte, empertigada e ativa base trumpista podem derrotar mesmo um candidato democrata preparado e sólido.

\section{REFERÊNCIAS}

ALLEN, J. Inside Trump's all-about-that-base 2020 strategy. NBC News, 8 April 2019. Disponível em: <https://is.gd/O1ocaT>. Acesso em: abr. 2019.

BACON JUNIOR, P. The five wings of the Republican Party. FiveThirtyEight, 27 Mar. 2019. Disponível em: <https://53eig.ht/2TBXgsg>. Acesso em: jan. 2019.

BALL, M.; ELLIOTT, P. The biggest field yet. No frontrunner. A divided base. Welcome to the 2020 democratic primary. Time, Feb. 21, 2019. Disponível em: $<$ https://is.gd/sEdV3Z>. Acesso em: fev. 2019.

BANNON, B. What happened to the Tea Party? The Hill, 14 Aug. 2018. Disponível em: <https://is.gd/F9sVkN>. Acesso em: fev. 2019.

BIANCO, W. T.; CANON, D. T. American Politics Today. 2nd ed. New York: W. W. Norton \& Company, 2011. p. 291-307.

BOYD, J. Nixon's southern strategy: 'it's all in the charts'. The New York Times. 17 May 1970. p. 215. Disponível em: <https://www.nytimes. $\mathrm{com} / 1970 / 05 / 17 /$ archives/nixons-southern-strategy-its-all-in-the-charts. html?searchResultPosition=1>. Acesso em: maio 2019. 
BRADY, D.; RIVERS, D.; PARKER, B. What 2018 tells us about the democrats' chances in 2020. The American Interest, 1 Jan. 2019. Disponível em: <https:// is.gd/uQOiYw>. Acesso em: mar. 2019.

BREMMER, I. Ignore the polls. Trump has a shrewd strategy to win back the White House in 2020. Time, 14 Mar. 2019. Disponível em: <https://is.gd/ WUJCe7>. Acesso em: abr. 2019.

BROWNSTEIN, R. Democrats' two roads to beating Trump. The Atlantic, 28 Feb. 2019a. Disponível em: <https://is.gd/N01Tld>. Acesso em: abr. 2019.

Trump settles on his reelection message. The Atlantic, Mar. 7, 2019b. Disponível em: <https://is.gd/VVs1Oa>. Acesso em: abr. 2019.

BURNS, B. Bill Weld will challenge Trump for 2020 republican nomination. The New York Times, 15 Feb. 2019. Disponível em: <https://www.nytimes. com/2019/02/15/us/politics/bill-weld-trump-2020.html?module=inline $>$. Acesso em: fev. 2019.

CILLIZZA, C. What the Ilhan Omar controversy reveals about the current state of the Democratic Party. CNN, 7 Mar. 2019. Disponível em: <https://is.gd/ mEtMly>. Acesso em: mar. 2019.

CILlufFO, A.; FRY, R. An early look at the 2020 electorate. Pew Research Center, 30 Jan. 2019. Disponível em: <https://is.gd/ple1 ta>. Acesso em: abr. 2019.

GALSTON, W. A.; HENDRICKSON, C. Report: the democrats' choice: the midterm elections and the road to 2020. Brookings, 30 Jan. 2019. Disponível em: <https://is.gd/QJVNdN>. Acesso em: mar. 2019.

JONES, J. Democratic states exceed republican states by four in 2018. Gallup, 22 Feb. 2019. Disponível em: <https://is.gd/ha2ItN>. Acesso em: fev. 2019.

KURTZLEBEN, D. Rural voters played a big part in helping Trump defeat Clinton. NPR, 14 Nov. 2016. Disponível em: <https://is.gd/JZZK6z>. Acesso em: fev. 2019.

MEAD, W. R. The Tea Party and U.S. foreign policy. The New York Times, 21 Feb. 2011a. Disponível em: <https://www.nytimes.com/2011/02/22/opinion/22ihtedrusselmead22.html?searchResultPosition=1>. Acesso em: dez. 2018.

. The Tea Party and American foreign policy: what populism means for globalism. Foreign Affairs, Mar./Apr. 2011b. Disponível em: <https://is.gd/ rSO11g>. Acesso em: dez. 2018.

MONKOVIC, T. 50 years of electoral college maps: how the U.S. turned red and blue. The New York Times, 22 Aug. 2016. Disponível em: <https://nyti. ms/2bzIRee>. Acesso em: jan. 2019. 
PECEQUILO, C. S. Os Estados Unidos de H. Bush a Donald J. Trump (1989/2017): dinâmicas políticas de consenso e polarização. Revista Esboços, Florianópolis, v. 24, n. 38, p. 339-359, dez. 2017.

PILKINGTON, E. Republican Bill weld announces he will take on Trump in 2020. The Guardian, 15 Feb. 2019. Disponível em: <https://is.gd/K4xOZA>. Acesso em: fev. 2019.

ROTHMAN, N. The democratic Tea Party they said wasn't possible is here. Commentary, 9 Apr. 2019. Disponível em: <https://is.gd/QtDQBg>. Acesso em: abr. 2019.

SAAD, L. U.S. still leans conservative, but liberals keep recent gains. Gallup, 8 Jan. 2019. Disponível em: <https://is.gd/As4EEF>. Acesso em: jan. 2019.

SAAD, L.; JONES, J. M.; BRENAN, M. Understanding shifts in Democratic Party ideology. Gallup, 19 Feb. 2019. Disponível em: <https://is.gd/9VkOKw>. Acesso em: fev. 2019.

SHEFFIELD, M. Biden takes 32-point lead over Sanders in new 2020 poll. The Hill, 6 May 2019. Disponível em: <https://is.gd/L9qK3V>. Acesso em: May 2019.

SMITH, D.; PILKINGTON, E. 'This is Trump's party': republicans eager to knock back 2020 challengers. The Guardian, 30 Mar. 2019. Disponível em: $<$ https://is.gd/pWCCUv>. Acesso em: mar. 2019.

SNELL, K. McConnell's 2020 plan: cast GOP as 'firewall' against socialism. NPR, 11 Apr. 2019. Disponível em: <https://is.gd/FWemjn>. Acesso em: abr. 2019.

STOLBERG, S. G. Republicans hope to sway voters with labels that demonize democrats. The New York Times, 17 Feb. 2019. Disponível em: <https://nyti. ms/2Ef6Tc5>. Acesso em: mar. 2019.

TEIXEIRA, T. A escolha de Obama. Revista Eletrônica Boletim do Tempo Presente, ano 6, n. 6, 2011.

. Eleiçóes 2020: disputa democrata já começou. Informe Opeu, 19 fev. 2019. Disponível em: <https://www.opeu.org.br/2019/02/19/eleicoes2020/>. Acesso em: fev. 2019.

THOMPSON, A. RNC assembles team to reelect Trump. Politico, 1 Mar. 2019. Disponível em: <https://is.gd/8rHbGU>. Acesso em: abr. 2019.

WOOD, J. Which republicans will take on Trump in 2020? The Guardian, 14 Feb. 2019. Disponível em: <https://is.gd/1EW3FM>. Acesso em: fev. 2019. 
